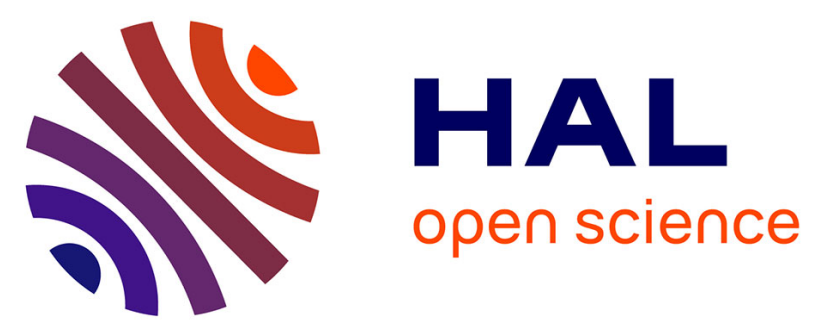

\title{
Chemical characterization and in vitro antioxidant capacity of nine Algerian date palm cultivars (Phoenix dactylifera L.) seed oil
}

Oum Kelthoum Laghouiter, Mohamed Benalia, Nadhir Gourine, Amar

Djeridane, Isabelle Bombarda, Mohamed Yousfi

\section{To cite this version:}

Oum Kelthoum Laghouiter, Mohamed Benalia, Nadhir Gourine, Amar Djeridane, Isabelle Bombarda, et al.. Chemical characterization and in vitro antioxidant capacity of nine Algerian date palm cultivars (Phoenix dactylifera L.) seed oil. Mediterranean Journal of Nutrition and Metabolism, 2018, 11 (2), pp.103-117. 10.3233/MNM-17185 . hal-02082992

\section{HAL Id: hal-02082992 \\ https://hal-amu.archives-ouvertes.fr/hal-02082992}

Submitted on 28 Mar 2019

HAL is a multi-disciplinary open access archive for the deposit and dissemination of scientific research documents, whether they are published or not. The documents may come from teaching and research institutions in France or abroad, or from public or private research centers.
L'archive ouverte pluridisciplinaire HAL, est destinée au dépôt et à la diffusion de documents scientifiques de niveau recherche, publiés ou non, émanant des établissements d'enseignement et de recherche français ou étrangers, des laboratoires publics ou privés. 


\title{
Chemical characterization and in vitro antioxidant capacity of nine Algerian date palm cultivars (Phoenix dactylifera L.) seed oil
}

\author{
Oum Kelthoum Laghouiter ${ }^{\mathrm{a}}$, Mohamed Benalia ${ }^{\mathrm{a}}$, Nadhir Gourine ${ }^{\mathrm{a}}$, Amar Djeridane ${ }^{\mathrm{a}}$, \\ Isabelle Bombarda ${ }^{\mathrm{b}}$ and Mohamed Yousfi ${ }^{\mathrm{a}, *}$ \\ ${ }^{a}$ Laboratoire des sciences fondamentales, Université Amar Telidji, Laghouat, Algérie \\ ${ }^{\mathrm{b}}$ Aix - Marseille Université, Univ Avignon, CNRS, IRD, IMBE, Marseille cedex 20, France
}

\begin{abstract}
Date pits are another major date palm crops and low grade rejected, used locally in the management of diabetes and as animal feed ingredient or turned into non-caffeinated coffee by the Arabs although their richness with valuable bioactive and antioxidant compounds. In this study and for the first time, lipids, fatty acids profiles, total tocopherols and sterols of nine (9) Algerian date palm cultivars (Phoenix dactylifera L.) seed oil were investigated and their antioxidant activities were evaluated. Oil yield ranged from $4.86 \%$ to $6.7 \%$. Gas liquid chromatography revealed that the oil fraction contained unsaturated fatty acids in majority with the preponderance of oleic acid (37.83-55.00\%) followed by lauric and myristic acids $(6.63-25.36 \%$ and $9.30-19.33 \%)$ respectively. The study of the unsaponifiable fraction revealed the presence of sterols and tocopherols. The sterols contents ranged from 4.7 to $8.45 \mathrm{mg} / \mathrm{g}$ DW. Whereas, the levels of total tocopherols ranged from 0.32 to $0.74 \mathrm{mg} / \mathrm{DW}$, which $\alpha$-tocopherol was the predominant tocopherol $(15.57 \%-74.1 \%)$ followed by $(\beta+\gamma)$-tocopherol $(25.12 \%-56.01 \%)$. The antioxidant activity of date seeds oil was determined with DPPH radical scavenging assays. The oils had a moderate bleaching effect on DPPH free radicals, where Ghars (GH), Sbo3 Lossif (SL) and Timjhourt (TIM) seed oils were the active ones.

The richest of date seed oil by active components such sterols, tocopherols also high amounts of oleic, lauric and other fatty acids suggest it to be as a useful source of edible oils for human consumption as well as using as additives in food, for medicinal use, in cosmetics, pharmaceuticals and food industries.
\end{abstract}

Keywords: Date seeds, lipids, fatty acids, sterols, tocopherols, antioxidant capacity

\section{Introduction}

Nuts and seeds are highly nutritious, and are of prime importance for people in several regions. Seeds of plants are rich sources of various kinds of lipidic compounds including triacylglyceriols (at levels above 90\%), fatty acids, tocopherols, phospholipids, sphingolipids and sterols present in different proportions [1]. Recently, many seeds have also been identified as being especially rich in antioxidants [2] which may contribute to their nutritious value. In Prunus amygdalus there is an array of flavonoids components in their aglycone and

\footnotetext{
${ }^{*}$ Corresponding author: Mohamed Yousfi, Laboratoire des sciences fondamentales, Université Amar Telidji, BP37G, 03000 Laghouat, Algérie. E-mail: yousfim8@gmail.com.
} 
glycoside forms. Arachis hypogaea and Pistacia vera contain several flavonoids, and are enriched in resveratrol, while Juglans regia contain a variety of typically non-flavonoid ellagitannins polyphenols and tocopherols. In Anacardium occidentale, alkyl phenols are found in abundance. These antioxidants, in cooperation with many other major and minor antioxidants in seeds, may potentially reduce oxidative stress and risk of related diseases [3].

The date palm (Phoenix dactylifera L.) is the most important fruit tree grown in Algeria and the Arab world due to its commercial and economic usefulness, where Algeria is among the leading countries in the cultivation and production of palms dates. Recent statistics indicate that the number of palm trees planted globally grown accounts for about 18 millions [4]. Nearly 1000 cultivars clonally propagated from offshoots have been inventoried and their distribution shows a very marked breakdown into eastern, central and western parts of the country. Some cultivars are found in two or three regions but most are restricted to their area of origin [5]. What is more, cultivars are not evenly distributed across oases, as they are adapted to slightly different types of soil, ranges of temperature and humidity, and often do not produce a satisfactory yield when cultivated outside their place of origin. Date seeds, pits or kernels considered as rejected part of date palm fruit (Phoenix dactylifera $L$, Arecaceae.); a perennial monocotyledonous plant that is native to the Middle East and North Africa [4, 5].

Date seeds are used locally in traditional medicine, as animal feed, artisan or turned into non-caffeinated coffee although their richness with valuable bioactive and antioxidant compounds. Dates contain storage material in the seed as starchy endosperm [5]. Moreover, Date seeds are excellent sources of carbohydrates and dietary fibers. Insoluble dietary fiber (hemicelluloses, cellulose, and lignin) is considered to be the major constituent of seed fiber [6]. In addition to being very rich sources of protein, they have many other benefits such as vitamins, minerals, carotenes, and other chemicals that may prevent cancer and heart disease [7, 8]. However, the chemical analysis showed that date palm seeds contain 5-12\% oil [7]. Equal amounts of saturated and unsaturated (mostly monounsaturated) fatty acids are present in date palm seed oil with the predominant of oleic acid followed by linoleic, lauric, palmitic and stearic acids [9, 10]. Their edible oil (which has antioxidant properties) is also rich with phenolics compounds (Hydroxytyrosol, protocatechuic acid, gallic acid, tyrosol, caffeic acid, pcoumaric acid, 3,4-dihydroxyphenylacetic acid and oleuropein) higher than olive oil [11]. Also, the palm seeds oil has an outstanding importance, not only as renewable resources (biodiesel) and cosmetics, but also in the production of some functional food products (long shelf-life) as well as nutraceuticals, pharmaceutical, and medicine industries (natural antioxidant) [11,12]. Date seeds are also listed in folk remedies for the management of diabetes, to relieve ague and toothaches, to lower the risk of cancer and some cardiovascular diseases as well as to improve the functionality and integrity of the immune system, for liver diseases and gastrointestinal disorders [13]. Moreover, antioxidants are the next major property present in date seeds [8]. However, there are no studies on fatty acid composition, antioxidant properties and the health benefits of the most Algerian date seeds oil.

Thus, the aim of this study was to gain further insight into phytochemical and nutrient compositions of nine Algerian date seeds cultivars include fatty acids profiles, sterols, and tocopherols composition. The antioxidant activity of the seed oil was also evaluated, thus establishing them as a potential natural source alternative to those synthetic antioxidants.

\section{Experimental procedure}

\subsection{Chemicals}

The chemicals used were of analytical reagent grade. Anhydrous sodium sulphate, sodium and ascorbic acid were purchased from AnalaR NORMAPUR Prolab. Chloroform, absolute ethanol, $n$-hexane, sulfuric acid, acetic acid, ferric chloride, dichloromethane, $\alpha$-tocopherol (Vitamin E) and DPPH• (1,1-diphenyl, 2-picrylhydrazyl) were obtained from Sigma-Aldrich. Butylated hydroxyanisole (BHA) and butylated hydroxytoluene (BHT) 
were purchased from Fluka chemie. ortho-phenanthroline was obtained from Biochem Chemopharma. Acetic anhydride was obtained from Merck and cholesterol from UCB Pharma.

\subsection{Plant material}

The seeds used in this study were isolated from nine date palm fruits cultivars grown in Metlili-Ghardaïa (600 Km oust Algeria) named locally; Ghars (GH), Tafzouine (TAF), Azerza (AZ), Aoucht (AO), Adela (AD), Dagla (DG), Timjhourt (TIM), Bint Qbala (BQ), Sbo3 Lossif (SL). The seeds of each date cultivars were washed, dried and then grounded to a fine powder and sieved.

\subsection{Extraction of oil}

The oil of each seed cultivars $(60 \mathrm{~g})$ was extracted using n-hexane in a Soxhlet apparatus for $6 \mathrm{~h}$. The lipids were weighed after the solvent evaporation using a rotary evaporator at $40^{\circ} \mathrm{C}$ and then stored in a freezer at $4{ }^{\circ} \mathrm{C}$ until analysis.

\subsection{Preparation and analysis of fatty acids methyl ester}

Fatty acids methyl esters of oil were prepared using the method described by AFNOR [14]. The lipids were firstly hydrolyzed to their fatty acids FA and then converted to fatty acids methyl esters (FAMES). A Chrompack CP 9002 gas chromatography, equipped with a split-splitless mode injection system, flame ionization detector (FID) and a DB23 capillary column $(30 \mathrm{~m} \times 0.32 \mathrm{~mm}$ i.d., $0.32 \mu \mathrm{m}$ film thickness $)$ was used to analyze the FAMES. Oven temperature was in isotherm mode $\left(250^{\circ} \mathrm{C}\right)$. Injector and detector temperatures were set at $250^{\circ} \mathrm{C}$. Nitrogen was used as carrier gas at a flow rate of $1 \mathrm{~mL} / \mathrm{min}$. The injection volume was $1 \mu \mathrm{L}$. The fatty acids were identified by comparing their retention times with those of pure standards. Fatty acid methyl esters were quantified as percentages $(\%)$ of the total methyl ester peak areas.

\subsection{Tocopherols analysis}

Total tocopherol content was quantified using colorimetric method as described by Emmerie-Engel [15]. $1 \mathrm{ml}$ of diluted sample solutions was mixed with $1 \mathrm{ml}$ of ortho-phenantroline, $0.4 \%$ and $0.5 \mathrm{ml} \mathrm{FeCl}$ (ethanolic solution $0.12 \%$ ). The mixture was incubated in the dark for $3 \mathrm{~min}$ and the red orange color formed is measured at $510 \mathrm{~nm}$ UV/VIS-1800 Shimadzu spectrophotometer. $\alpha$-tocopherol was used as the standard for the calibration curve. The results are expressed as $\mathrm{mg} \alpha$-tocopherol equivalent per gram of oil ( $\mathrm{mg} \alpha$-TE/g oil).

The tocopherol compounds were quantified by HPLC using an Agilent 1290 Infinity apparatus equipped with a Quaternary Pump Model 1260, an automatic liquid sample and a fluorimetric detector (FLD 1260). The detection was set at $295 \mathrm{~nm}$ for excitation wavelength and at $330 \mathrm{~nm}$ for emission wavelength. The separation column was a SI60 (250 mm $\times 4.6 \mathrm{~mm}$ i.d., $5 \mu \mathrm{m}$, Lichrosorb, Merck KGaA Darmstadt, Germany). The mobile phase was n-hexane/isopropanol, 99/1, v/v, in isocratic mode, with a flow rate set at $1 \mathrm{~mL} / \mathrm{min}$, during $20 \mathrm{~min}$. Column compartment was set at $25^{\circ} \mathrm{C}$. Commercial standard ( $\alpha$-tocopherol) and a mixture $(\alpha, \beta, \gamma$, and $\delta$ - tocopherol) were co-injected with samples for the identification of tocopherol isomers.

\subsection{Determination of total sterols content}

The total content of sterols was determined using the Lieberman-Burchard assay $[16,17] .1 \mathrm{ml}$ of diluted sample solutions was mixed with $2 \mathrm{ml}$ of Lieberman-Burchard Reagent (Liebermann reagent constituted of $60 \mathrm{ml}$ anhydrous acetic $+10 \mathrm{ml}$ concentric sulfuric acid $+30 \mathrm{ml}$ acetic acid). The mixture was incubated in the dark for $30 \mathrm{~min}$ and the green color formed was measured at $550 \mathrm{~nm}$ using a UV/VIS-1800 Shimadzu spectrophotometer. 
Cholesterol was used as the standard for the calibration curve. The results are expressed as mg cholesterol equivalent per gram of oil (mg CE/g oil).

\subsection{Measurement of antioxidant capacity}

The in vitro antioxidant activity of the nine seed oil was assayed using DPPH (1, 1-Diphenyl-2-picryl-hydrazyl) radical scavenging assay. The DPPH radicals assay was assessed as described by Molyneux et al. [18] method with slight modifications. The reaction mixture contained $1 \mathrm{~mL}$ of date seed extract at different concentrations and $1 \mathrm{ml}$ of ethanolic DPPH $(250 \mu \mathrm{M})$. The mixture was incubated at room temperature for $30 \mathrm{~min}$ and the absorbance was determined at $517 \mathrm{~nm}$ using a UV/VIS-1800 Shimadzu spectrophotometer. The half-maximal effective concentration EC50 values were calculated from the plotted graph of scavenging activity against the concentrations of the samples. Ascorbic acid, $\alpha$-tocopherol and BHT were used as a positive control. All the measurements were taken in triplicate and the mean values were calculated.

\subsection{Statistical analysis}

Results are presented as means \pm SD from three replicates of each experiment. Statistical analysis of data was carried out by computer using MS-Excel. Strictly linear calibration curves were obtained for all of the methods using different calibration standards.

\subsection{Cluster analysis}

Cluster analysis (CAH) was performed using hierarchical clustering (Ward's technique) with Euclidean distance measure using XLSTAT 7.5.2. The calculus was performed using two sets of data. The first set of data which refer to the analysis of Fatty acids which composed 22 different oils plants and 11 variables. Whereas, the second set of data which refer this time to the analysis of tocopherols $(\alpha-,(\beta+\gamma)-$, and $\delta$-tocopherol) is composed of 30 oils of different plants and 3 variables.

\section{Results and discussion}

\subsection{Oil seed content}

In this investigation, all examined date seeds oils were semi solids with pale yellowish color and a pleasant odor due to methyl nonyl ketone $[7,12,19]$. This color may be attributed to the presence of an important quantity of carotenoids which is responsible of the strong absorbance of this oil in 418-470 $\mathrm{nm}$ [12].

Table 1 shows the oil content of the nine studied palm cultivars seed oils. The oil content varied between $4.86 \%$ and $6.70 \%$ DW. The contents of TIM $(6.43 \%$ DW), GH $(5.64 \%$ DW) and TAF $(5.67 \%$ DW) showed similar amounts with the same varieties in the study of Boukouada et al. [20] (TIM 6.08, GH 5.05 and TAF 5.4\% DW). Moreover, our results are similar to those found by Bouhlali et al. [21] (5.662-6.972\% DW) and those found for Sorghum bicolor seeds (6.2-6.5\% DW) [22]. On the other hand, these values were generally lower than those found in date seed oil extracted with petroleum ether $(10-12 \% \mathrm{DW})[11,23]$ and other seeds such Cucurbita pepo seeds (15.8-33.5\% DW) [24], Prunus dulcis oil (50\% DW), Prunus armeniaca kernel oil (40-45\% DW) and Carya illinoinensis oil (65\% DW) [19].

These differences in the oil concentration may be attributed to the normal variability of the cultivars, to the different environmental factors and farming practices, to the method and solvent used for extraction. Although date seeds cannot be considered as an oleaginous seeds or as oil-bearing seeds, such as Arachis hypogaea, Olea europaea and Helianthus annuus seeds, which possess 30-40\% oil, their oil contents were in the range of other 
Table 1

Oil content and fatty acids composition of the nine date seed oil

\begin{tabular}{lccccccccc}
\hline & AD & AO & AZ & BQ & DG & GH & SL & TM & TF \\
\cline { 2 - 9 } Oil \% & 5.43 & 5.23 & 5.64 & 6.70 & 5.60 & 5.64 & 4.86 & 6.43 & 5.67 \\
\hline C12:0 & 16.59 & 11.52 & 6.63 & 15.08 & 13.82 & 11.26 & 25.36 & 24.68 & 21.23 \\
C14:0 & 14.14 & 9.30 & 10.74 & 14.57 & 13.04 & 13.39 & 17.17 & 13.55 & 19.33 \\
C16:0 & 9.99 & 17.59 & 12.43 & 11.04 & 10.63 & 11.71 & 10.24 & 9.99 & 9.63 \\
C16:1 & - & 1.65 & 1.66 & 0.11 & 0.12 & 0.12 & 0.51 & 0.09 & 0.17 \\
C17:0 & 0.08 & - & - & - & - & 0.10 & - & - & 0.86 \\
C18:0 & 2.65 & 0.77 & 1.85 & 2.31 & 3.18 & 2.65 & 1.43 & 3.4 & - \\
C18:1 & 46.56 & 52.53 & 55 & 47.18 & 49.66 & 50.41 & 37.83 & 40.85 & 37.89 \\
C18:2 & 9.22 & 5.71 & 8.95 & 8.73 & 8.2 & 9.46 & 7.22 & 6.41 & 10.44 \\
C18:3 & - & 0.41 & 0.59 & 0.12 & 0.23 & 0.10 & - & - & 0.16 \\
C20:0 & 0.33 & 0.24 & 1.47 & 0.36 & 0.50 & 0.36 & 0.22 & 0.45 & 0.10 \\
C20:1 & 0.41 & 0.26 & 0.65 & 0.48 & 0.61 & 0.43 & - & 0.37 & 0.16 \\
\hline SFA & 43.8 & 39.43 & 33.13 & 43.37 & 41.18 & 39.48 & 54.42 & 52.27 & 51.16 \\
UFA & 56.19 & 60.56 & 66.87 & 56.62 & 58.82 & 60.52 & 45.57 & 47.72 & 48.83 \\
\hline UFA/SFA & 1.28 & 1.53 & 2.02 & 1.30 & 1.43 & 1.53 & 0.83 & 0.91 & 0.95 \\
\hline
\end{tabular}

UFA: Unsaturated fatty acids; SFA: Saturated fatty acids. $n=1$.

vegetable oils that are used as health components or have industrial or pharmaceutical applications, as in the case of Triticum vulgare, Quercus fruits and Sorghum bicolor seeds, which have "less than $10 \%$ fat content" [22].

\subsection{Fatty acid analysis}

The FAMES compositions of date seed oils were analyzed. Table 1 shows the fatty acid composition of the nine studied palm cultivars seed oils. Thirteen (13) fatty acids were identified in our seeds oil. According to the literature, date seeds containing 14 types of fatty acids but only 8 occur in very low concentration in the flesh [25]. As shown in Table 1, the major founded fatty acids were: oleic, lauric, myristic, palmitic, linoleic and stearic acids. Oleic acid was the dominant fatty acid in most of the seeds up to $40 \%$ it ranged from $37.83 \%$ for SL cultivar to $55.00 \%$ for AZ, followed by lauric acid (6.63\% for AZ cultivar to $25.36 \%$ in SL), then myristic, palmitic and linoleic acids with about $(9.30-19.33 \%, 9.63-17.59 \%$ and $5.71-10.44 \%)$ respectively. Whereas, Gadoleic, arachidonic and linolenic acids are present in relatively lower amount, while capric, margaric acids were present in negligible amounts.

As all examined date seeds oils are rich in both oleic and lauric acid which allows classifying this oils in Oleic- Lauric category, they may be used as edible cooking oil, as salad oil, or for the manufacture of margarine. The high percentage of oleic acid in the oil makes it desirable in terms of nutrition and high stability cooking and frying oil. The oleic acid plays an important role for the prevention of the cardiovascular disease. Oleic acid which categorized as long chain fatty acid that is taken in diet is increased the high density lipoprotein (HDL) content in blood, at the same time lowering the low density lipoprotein (LDL) content [8]. The relatively high degree of instauration allows the oils to oxidize easily when used for deep-fat frying. Therefore, edible oil industry has focused attention on high oleic vegetable oils such as high oleic Zea mays; Helianthus annuus and Brassica napus have been found to have enough oxidative stability to be used in demanding applications such as frying [26].

However, saturated fatty acids ranged from $33.13 \%$ (AZ) to $54.42 \%$ (SL). Lauric acid was the major saturated fatty acid constituent, with percentages of $6.63 \%$ and $25.36 \%$ for AZ and SL, respectively, followed by myristic, 
palmitic and stearic acids. These findings are very close to the results presented by Al-Juhaimi et al. [27]; Besbes et al. [7]; Sawaya et al. [28] and Bouhlali, et al. [21] but higher than those found by Boukouada et al. [20], similar to Sorghum bicolor seeds oil [22], Algerian Argania spinosa seeds oil [29] and Prunus cerasus seeds (46\%) but lower than other fruits seeds like Prunus armeniaca and Prunus persica seeds oil (68\% and 69\%) respectively [30]. However, Al-Hooti et al. [31] found a higher content of oleic acid (53.3-58.8\%) in date seed oil from other origins. On other hand, the main fatty acids of oil extracted from Phoenix canariensis seeds analyzed by GC/MS were oleic $(50.10 \%)$, linoleic (19.23\%), lauric (10.24\%), palmitic $(9.83 \%)$ and stearic $(7.51 \%)$ acids [32].

Comparing the instauration degree of the studied oils with the commonly consumed vegetable oils, the date seed oils had a relatively lower degree of instauration and a lower amount of linoleic acid. Despite this low level of instauration, date seed oils have potential use in human and/or animal diets [28]. The unsaturated fatty acids, oleic and linoleic acids, were detected in all oils with some minor differences, all seed oils fatty acid profiles were much the same. The values of the $\mathrm{U} / \mathrm{S}$ ratio $(\mathrm{U} / \mathrm{S}=$ unsaturated fatty acids/saturated fatty acids) were 0.83 for SL and 2.02 for AZ. These ratios were less than those found for Algerian Argania spinosa oil (2.1) [29], Pistacia atlantica fruits oil (2.7) [33], Cucurbita pepo seed oils (4.46) [24] and Sorghum bicolor grains oils (>5.7) [22]. These values give the oils a good prevention of oxidation.

Based on the fatty acid composition, date seeds seem to be a useful source of edible oils for human consumption. It is clear that date seeds contain an important amount of UFA (45.57\%-66.87\%), such as linoleic acid known as omega 6 FA, which is an essential dietary requirement; it found as the major FA of other seeds such Helianthus annuиs oil, Glycine max oil, and Sesamum indicum oil. This essential fatty acid is the precursor of prostaglandins and is involved in structural membranes [34, 35]. In addition, the high amount of lauric acid of these date seeds oils can be decreased significantly. Total Cholesterol (TC)/high density lipoprotein cholesterol (HDL-C) ratio compared with carbohydrate consumption [21]. The linoleic acid is widely used in cosmetic products as it helps to heal dermatoses, sun burns and effectively treat acne vulgaris. Moreover, some studies found that the date seed oil could repair the human skin which could be due to the antioxidant activity [21,32]. Therefore, date seed oil could be a good ingredient for cosmetic and pharmaceutical products such as sun-block creams that provide protection against both UV-A and UV-B, which are responsible for cellular damage. In general, fatty acid composition of date seed oils may be affected by differences between varieties, cultural conditions and climatic conditions [36].

\subsection{Sterols content}

Sterols were found to be major component of the unsaponifiable fraction. Phytosterols occur mainly as esterified sterols in oils and fats, the forms accumulated in the membranes and in oil droplets. However, each form may contribute about $10-15 \%$ of all sterols in cereals [37].

As shown in Table 2, high levels of sterols were determined in all examined seeds oils. Their content varied between $4.70 \pm 0.06$ and $8.45 \pm 0.01 \mathrm{mg} / \mathrm{g}$. AO seeds oil presented the lowest value while TAF seed oil was the richest one. The sterol content was in the range of other vegetable materials; Zea mays $(23 \mathrm{mg} / \mathrm{g})$,

Table 2

Tocopherols and sterols spectrophotometric quantification of the nine date seed oil. $n=3$ or $5, \pm \mathrm{SD}$

\begin{tabular}{lccccccccc}
\hline & AD & AO & AZ & BQ & DG & GH & SL & TAF & TIM \\
\hline Tocopherol (mg $\alpha$-TE/g oil) & $0.41 \pm$ & $0.54 \pm$ & $0.32 \pm$ & $0.48 \pm$ & $0.44 \pm$ & $0.62 \pm$ & $0.74 \pm$ & $0.59 \pm$ & $0.65 \pm$ \\
& 0.03 & 0.01 & 0.01 & 0.01 & 0.01 & 0.01 & 0.03 & 0.07 & 0.03 \\
Sterols (mg CE/g oil) & $7.04 \pm$ & $4.7 \pm$ & $7.53 \pm$ & $6.35 \pm$ & $6.15 \pm$ & $5.48 \pm$ & $7.86 \pm$ & $8.45 \pm$ & $6.14 \pm$ \\
& 0.01 & 0.06 & 0.01 & 0.08 & 0.01 & 0.03 & 0.02 & 0.01 & 0.01 \\
\hline
\end{tabular}

$\alpha$-TE: $\alpha$-tocopherol equivalent; CE: cholesterol equivalent. 
Glycine max $(9 \mathrm{mg} / \mathrm{g})$, Brassica napus seed $(5 \mathrm{mg} / \mathrm{g})$, Cocus nucifera $(0.80 \mathrm{mg} / \mathrm{g})$ and Prunus armeniaca Kernel $(0.8 \mathrm{mg} / \mathrm{g})$. The Sterol content in our date seeds oils is very close to that established by Boukouada and yousfi, [38] (5.40-7.84 mg/g) but higher than those found by Tunisian date seeds (3.0-3.5 mg/g oil) [7], Phoenix canariensis seed oil (3.36 mg/g oil), (Aronia) melanocarpa seed oil $(1.2 \mathrm{mg} / \mathrm{g})$, palm kernel oil (1056 mg/kg oil) and extra virgin Olea europaea oil $\sim 1500 \mathrm{mg} / \mathrm{kg}$. However the majority of other vegetable oils contained much lower esterified sterols content (25-40\%) [11]. Existing differences between sterol compositions make them the most suitable for determining the botanical origin of oils and hence detecting adulteration among vegetable oils. In fact, Brassica napus seed oil contains a significant amount of brassicasterol, while Olea europaea oil has a high level of $B$-sitosterol and $\Delta 5$-avenasterol. Meanwhile, Helianthus annuus seed oil has a high level of $\Delta 7$-stigmastanol. Thus, date seed oils, similar to Olea europaea oils, contain a high level of $B$-sitosterol. Both genetic differences, ripening growing location and postharvest storage, water stress during the growing period may change sterol contents and compositions of fruits or vegetables. Literatures reporting that the major components of date seeds oil sterols were $\beta$-sitosterol ( $>70 \%)$, flowed by campesterol (10\%) accompanied with minute amounts of cholesterol, stigmasterol, 7-stigmastenol and $\Delta 5$-avenasterol [11]. These values are similar to other seeds oil with nearly amounts such as: Phoenix canariensis seed oil, Prunus armeniaca seed oil, Prunus persica seed oil, Prunus cerasus seed oil, Opuntia ficus-indica and Bulgarian Vitis aestivalis seed oil [32, 30]. Furthermore, Besbes et al. [11] proved the presence of these sterols in date seeds. The minor components are not only very important for the functional properties of oils (oxidation resistance, taste, aroma, and color), but could also have many health benefits. Sterols from vegetable oils have been shown to lower total and LDL cholesterol levels in humans by inhibiting cholesterol absorption from the intestine [39]. These finding may lead to the use of date seed oil sterols as new therapeutic agents for treatment of hypercholesterolemia.

\subsection{Tocopherols analysis}

The main components of unsaponifiables in vegetables oils are tocopherols and sterols, present in different amounts in vegetable oils. Tocopherols with its four different forms $(\alpha, \beta, \gamma$ and $\delta$-tocopherol) are known to be very efficient natural antioxidants that protect lipids and other biological membrane components by physically quenching and reacting chemically with singlet oxygen; they are about 250 times more effective than butylated hydroxytoluene BHT [40]. Their amount in plant is probably related to the content of unsaturated fatty acids [40]. The tocopherols may protect against atherogenesis by blocking oxidation of low density lipoprotein cholesterol and by favorably influencing plaque stability, vasomotor function, and tendency for thrombosis [37]. In addition, tocopherols (vitamin E), due to their ability to quench free radicals in cell membranes, protecting polyunsaturated fatty acids from damage, play a significant role in prevention of Alzheimer's disease and cancer [41]. They have widely been used for food, feed, pharmaceuticals, cosmetics and resins [11]. It has been showed that the combination of $\alpha$-tocopherol with myricetin has increased the effectiveness of these antioxidants protection effect [42]. Seed oils such as Glycine max, Helianthus annuus and Arachis hypogaea, which contain high concentrations of total tocopherols, are the major sources of vegetable oil in the world [43].

The total tocopherol content of the studied date seeds oil that detected through the study is listed in the Table 2. The average tocopherol of our date seeds oil was $0.32 \pm 0.01$ and $0.74 \pm 0.03 \mathrm{mg} / \mathrm{g}$ oil for AZ and SL respectively as shown in (Table 2). These results are higher than those presented by Tunisian and Iranian date seed $(1.86 \mathrm{mg} / 100 \mathrm{~g}-2.19 \mathrm{mg} / 100 \mathrm{~g})$ [12, 44], Sorghum bicolor seed oil $(0.17-0.32 \%)$ [22], Cucurbita pepo seed oil (0.1-0.22 mg/g oil) [24], Phoenix canariensis seed oil ( $0.51 \mathrm{mg} / \mathrm{g}$ oil) [32], Prunus armeniaca seeds (3.10-22.45 $\mu \mathrm{g} / \mathrm{g})$, Jatropha curcas seed oil (199 mg/Kg), Vitis aestivalis seeds (353-688 $\mu \mathrm{g} / \mathrm{g}$ oil) [30] and Argania spinosa seed oil (1.02 mg/g) [29]. Moreover, these values are in the range of those found by Boukouada et al. [20] $(0.53-1.41 \mu \mathrm{g} / \mathrm{g})$.

The quantification of different forms of vitamin E, found in our date seed oil is recorded in the Table 3. The percentage of $\alpha$-tocopherol ranged between 15.57 to $74.10 \%$; where AZ had the lowest level, and TIM had the highest level. Furthermore, for $(\beta+\gamma)$-tocopherol, it ranged between $25.12 \%$ and 56.01\%; for TIM and AZ 
Table 3

Percentage and tocopherols composition of the nine date seeds oil, $n=1$

\begin{tabular}{lccccccccc}
\hline & AD & AO & AZ & BQ & DG & GH & SL & TAF & TIM \\
\hline$\alpha$-tocopherol & 57.53 & 56.84 & 15.57 & 70.17 & 39.53 & 60.05 & 64.82 & 50.65 & 74.1 \\
$(\beta+\gamma)$-tocopherol & 39.25 & 43.16 & 56.01 & 29.83 & 42.07 & 39.95 & 33.53 & 33.68 & 25.12 \\
$\delta$ - tocopherol & 3.23 & 0 & 28.41 & 0 & 18.39 & 0 & 1.64 & 15.67 & 0.78 \\
\hline
\end{tabular}

Table 4

Antioxidant capacity of standards

and date seed oils as measured using

the DPPH assay. $n=3$ or $5, \pm \mathrm{SD}$

\begin{tabular}{ll}
\hline Variety & $\mathrm{EC}_{50}(\mathrm{mg} / \mathrm{ml})$ \\
\hline $\mathrm{AD}$ & $64.10 \pm 0.10$ \\
$\mathrm{AO}$ & $53.95 \pm 0.19$ \\
$\mathrm{AZ}$ & $77.58 \pm 0.27$ \\
$\mathrm{BQ}$ & $56.82 \pm 0.06$ \\
$\mathrm{DG}$ & $55.13 \pm 0.18$ \\
$\mathrm{GH}$ & $46.97 \pm 0.01$ \\
$\mathrm{SL}$ & $46.42 \pm 0.14$ \\
TAF & $59.21 \pm 0.39$ \\
TIM & $47.97 \pm 0.06$ \\
BHA & $0.015 \pm 0.001$ \\
BHT & $0.015 \pm 0.001$ \\
Ascorbic acid & $0.009 \pm 0.001$ \\
$\alpha$-tocopherol & $0.033 \pm 0.002$ \\
\hline
\end{tabular}

respectively. Whereas, for $\delta$-tocopherol, AZ had the highest value with $28.41 \%$, but it is not identified in GH, $\mathrm{AO}$ and $\mathrm{BQ}$ seeds oil. However our results are in the range or higher than other commercial vegetable oils. Low levels found by Boukouada et al. [20] (42.80-62.50\%) and Habib et al. [4] (44.69\%) for Algerian and United Emirate Arabian date seeds with the difference of the presence of $\alpha$-tocopheryl acetate and vitamin K1, higher than those of Tunisian date seed oil (24.97-38.85\%) [11] with the predominance of $\alpha$-tocopherol in all date seed oils. Nehdi et al. [32] determined a different trend with $\gamma$-tocopherol being the predominant component for Phoenix canariensis, Cucurbita pepo seed oil, Sorghum bicolor oil, Glycine max oil, Zea mays seed oil, Jatropha curcas and Passiflora edulis seed oil were rich in $\gamma$ and $\delta$ tocopherol which classified as inactive isomer $[43,45]$.

The unidentified peaks may correspond to tocotrienols which are a part of vitamin E family with the four isomer $\alpha, \beta, \gamma$ and $\delta$-tocotrienol. The predominance of one or the other tocopherols depends on the oil origin. Siles et al. [46] in their study reported that several palm trees principally accumulate tocotrienols, rather than tocopherols, in seeds, as it occurs in other monocots. Nehdi et al. [32] reported that $66 \%$ of $\alpha$-tocotrienol possesses the highest tocopherols content found in Tunisian date seed oil. The other tocopherols found in this date seed oil were $\gamma$-tocopherol, $\gamma$-tocotrienol, $\delta$-tocopherol, $\beta$-tocopherol and $\alpha$-tocopherol with content value of $10.3 \mathrm{mg} / 100 \mathrm{~g}$, $4.6 \mathrm{mg} / 100 \mathrm{~g}, 1.0 \mathrm{mg} / 100 \mathrm{~g}, 0.9 \mathrm{mg} / 100 \mathrm{~g}$ and $0.6 \mathrm{mg} / 100 \mathrm{~g}$ respectively. Tocotrienols are generally present in small amounts in food lipids, except in palm oil, Vitis aestivalis seed oil, annatto lipid fraction and Oryza sativa $L$ oil, which has a relatively high content of these active components. 
The tocopherol concentrations in the date seed oils obtained in this study were much lower than those for oleaginous seeds. The oils contain an important quantity of other phenolic compounds other than tocopherols which could interfere in the quantification of the total phenolic compounds using a spectrometric method. In fact, the Emmerie-Engel method is reported to detect all phenolic compounds present in the oil; also the ferric ions could be reduced by other constituents beside phenolic compounds, such as carotenoids and vitamin A present in the oils $[47,20]$. Moreover, vitamin E deficiency affects nervous system development in children and hemolysis in humans. People with low vitamin E intake may be at increased risk of atherosclerosis [47]. This vegetable oil of date seeds is rich in oleic acid and linoleic acid which is of interest in food, rich in sterols and tocopherols known by their controlling effect against cancer, diabetes, and arthritis and Cardiovascular diseases and also for their antioxidant activity.

\subsection{Antioxidant activity}

Antioxidants can be classified into two major types based on their source, i.e., natural and synthetic antioxidant. Synthetic antioxidants such as butylated hydroxyanisole (BHA) and butylated hydroxytoluene (BHT) are purposely added to preserve flavor, color, and to avoid vitamin destruction of the food or any related products [48]. Natural antioxidant could be extracted in the form of phenolic compounds (flavonoids, phenolic acids and alcohols, stilbenes, tocopherols, tocotrienols), ascorbic acid and carotenoids. All of these antioxidants are different in their effectiveness. Both tocopherols and tocotrienols are also known collectively as vitamin E [49]. Some of these compounds were found in date seed oil: hydroxytyrosol, protocatechuic acid, tyrosol, gallic acid, caffeic acid, p-coumaric acid and oleuropein [11].

In this study, the antioxidant activity was estimated using 1, 1-diphenyl-2- picrylhydrazyl (DPPH) radical cations assay. Tree nut oil extracts were assayed over a range of dilutions to establish the concentration of each extract required to scavenge $50 \%$ of the DPPH radical present in the assay medium, referred to as the EC50.

Table 4 summarizes the results of antioxidant power, which showed a significant difference between date seeds oil varieties. All the oils exhibited good radical-scavenging activity for the bleaching of free DPPH radical. However, the $\mathrm{EC}_{50}$ values of standards which ranged from 9 to $33 \mathrm{mg} / \mathrm{l}$ were stronger than all tested oils. The $\mathrm{EC}_{50}$ values were in the range of $46.42 \pm 0.14-77.58 \pm 0.27 \mathrm{~g} / \mathrm{l}$. The antioxidant activity of the oils deceased in the following order: $\mathrm{SL}>\mathrm{GH}>\mathrm{TIM}>\mathrm{AO}>\mathrm{DG}>\mathrm{BQ}>\mathrm{TAF}>\mathrm{AD}>\mathrm{AZ}$. The lowest value was detected for the seed oil of SL variety, which corresponds to the highest antioxidant activity; while the highest value of $\mathrm{EC}_{50}$ was detected for the seed oil of AZ variety. The relatively strong antioxidant activities of SL oil extracts may be due to their high content of $\alpha$-tocopherol $(0.74 \pm 0.03 \mathrm{mg} / \mathrm{g}$ oil $)$.

However, EC50 values of all oil extracts had significant correlation with their actual tocopherol contents with coefficient $\left(R^{2}=0.75\right)$ as well as with $\alpha$-tocopherols content $\left(R^{2}=0.62\right)$. This may indicates that tocopherols which are polyphenolic components present in the oil extracts contributed to the total antioxidant capacity of the extracts even in small amounts. Boukouada et al. [20] demonstrated that antioxidant activity of date seed oil is attributed to their phenolic component $(0.64-1.27 \mathrm{mg} / \mathrm{g})$. Besides tocopherols, other antioxidative minor components of date seed oils include phospholipids [50], phytosterols and phytosterol conjugates [51], and possibly non-tocopherol phenolics, among others [52]. Synergistic antioxidant activities have been reported between tocopherols and nitrogen containing phospholipids such as phosphatidylcholine, phosphatidylethanolamine and phosphatidylserine [53], which may help explain the high antioxidant activities observed in this work.

Nevertheless our results were in the range of those presented by Iranian and Arabian Saoudi date seed oils with levels of 55.50\%-5.10\% and 78.03-79.94 g/l [54], but higher than those found by Boukouada et al. [20] for GH and TAF seed oil. It was declared that the antioxidant activity of the Date seed oils may be attributed to different components. This activity may have been partly contributed by some constituents other than fatty acids e.g. tocopherols and phenolic compounds. Further studies concerned content and composition of examined date seed oil should be done. 
In conclusion, the DPPH radical scavenging capacity of these oil extracts except TAF and DG have not previously been reported. Then, the consumption of foods rich in natural antioxidants has been reported as being protective against certain types of cancer and may also reduce the risk of cardiovascular and cerebrovascular events [55].

\subsection{Cluster analysis}

There are many possible techniques for classification of data. Principal Component Analysis (PCA) is commonly used technique for data classification and dimensionality reduction. PCA, as well as Cluster Analysis (CA) have been successfully applied using fatty acid profile as variable data set for food quality evaluation and the differentiation or classification of food samples. The CA includes mathematically applications to each data in terms of the multidimensional space characterized by the chosen variables. Thus, in order to characterize and classify our oil samples according to their fatty acid composition with other common plants (data provided from the literature), we have chosen the method of cluster analysis, using Ward's technique; 11 fatty acids representing the main compounds in these plants ( 31 individuals) were employed.

The results show the existence of three principal clusters (I, II and III) within the fatty acids of the individuals of the investigated plants (Fig. 1). Group (I) cluster gathers the flowing plants: Cocos nucifera, Orbignya oleifera and Elaies guinensis. The second Group (II) can be separated to two subgroups SG-1 and SG-2. The first subgroup (SG-1) is referred to the following plants: Prunus cerasus, Brassica campestris, Prunus amygdalus dulcis, Carya Illinoensis, Prunus armeniaca, Prunus persica, Prunus amygdalus dulcis, Olea European, Persea gratissim, Pistacia atlantica, Argania spinosa and Arachis hypogaea. The second subgroup (SG-2) includes, Phoenix Canariennes and our studied Phoenix dactylifera cultivars. This result indicates that our seeds oil is dietary plants oils. This cluster shows that the seeds of Algerian Dates (AD, BQ, DG, GH, AO and AZ) are very similar to those of Phoenix Canariennes in terms of nutritional effects (fatty acids compositions values). Moreover, TIM, SL and TAF cultivars are more alike than those further apart. The date palm cultivars are clearly separated from the other plants. The third group (III) is referred to the rest of plants: Gossypum herbaceum, Sorghum bicolor, Glycine soja, Glycine max, Heliantus annuus and Vitis vinifera. The main differentiation of these three groups is attributed mainly to the very low content of both lauric and myristic acids in the second and third group while their content in the first group were $47.8 \%$ and $21.17 \%$ respectively. The second group which our studied date seeds belongs is characterized by the high level of oleic acid (55.62\%), linoleic acid $(16.84 \%)$ and the same amounts of lauric, myristic and palmitic acids in the range of 6 to $10 \%$. The third group which contains Helianthus annuus, Gossypium sp, Sorghum bicolor characterized by high level of linoleic acid $(58.38 \%)$ less than the second group the amount of oleic (21.82\%) and palmitic (13.08\%) acids.

In the case of the tocopherols, the dendrogram of the (Fig. 2) indicates the presence of two main groups I and II. The second group can divided in two subgroups SG-1 and SG-2. The first group which included the examined date seeds oils individuals is referred to the cluster of the following plants: Arachidis hypogaea, Gossypum herbaceum, Persea gratissima, Maclura ponmifera, Cocus nucifera and Pistacia Atlantica in the first class the second class contained: Carica papaya L, Syagrus romanzoffiana), Citrus sinensis L, Citrus limon, Heliantus annuиs, Olea europaea, Prunus dulcis, Hymenaea courbaril, Prunus armeniaca, Phonix canariennes, Sesamum indicum, Prunus persica and Jatropha curcas, Cucumis melo L, Elaies guinensis, Brassica campestris, Argania spinosa and Tamarindus indica. While, the second subgroup which AZ belongs to comprises: Surghum bicolor, Glycine max and Cucurbita pepo.

The differentiation of these classes is attributed mainly to the difference of the three tocopherols where the first group included the studied date seeds oils is characterized by the high contents of $\alpha$-tocopherol ( $>60 \%)$ while the first class in the second group is characterized by the highest contents of $(\beta+\gamma)$-tocopherol $(80 \%)$. The SG-2 which contains AZ seed oil is characterized by the highest contents of $\delta$ and $(\beta+\gamma)$-tocopherol $(43.76 \%-47.28 \%$ respectively) but low content of $\alpha$-tocopherol. 


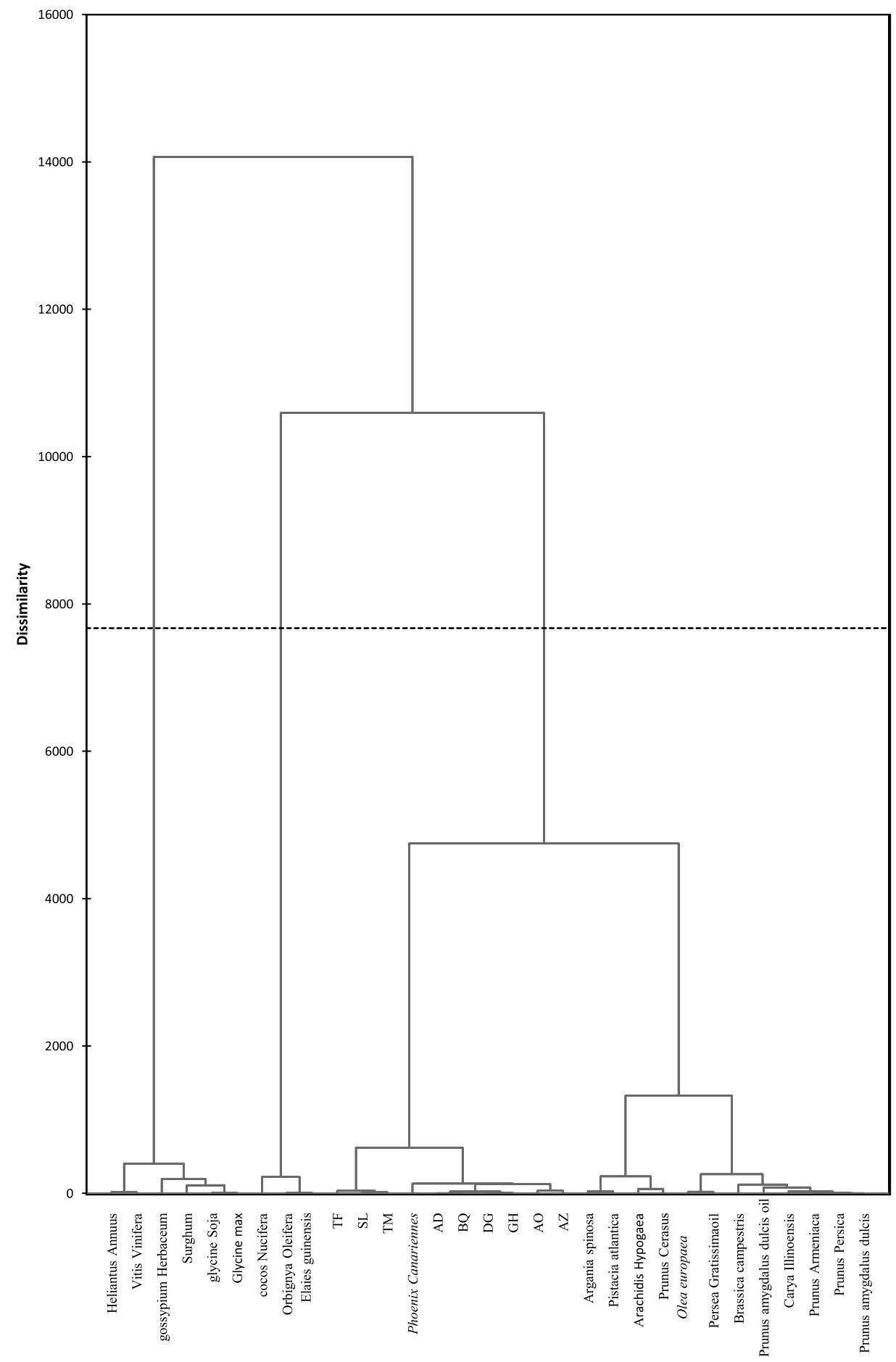

Fig. 1. Dendrogram obtained from the fatty acids cluster analysis of the nine studied Date seeds and 22 different plants oils. 


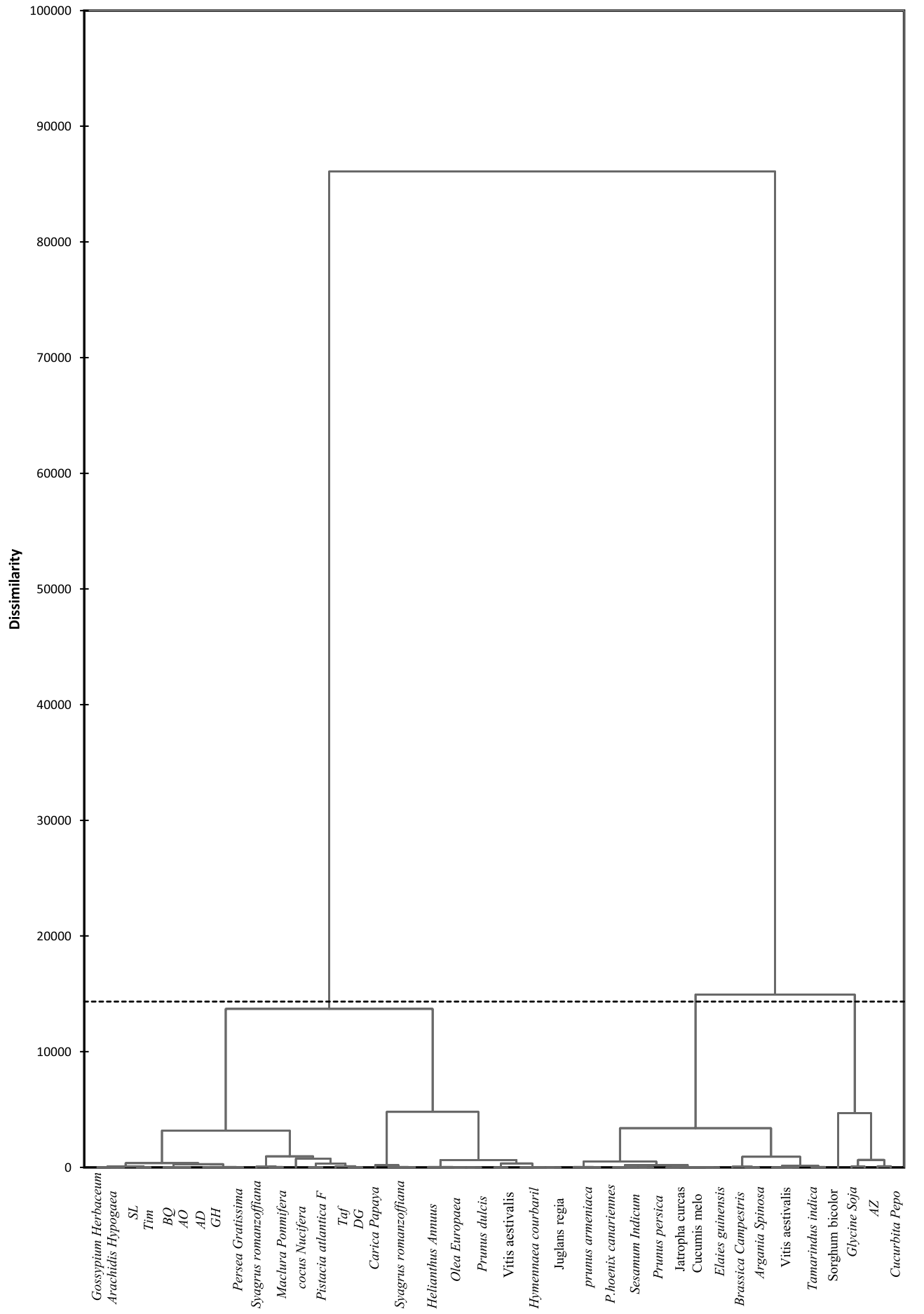

Fig. 2. Dendrogram obtained from the tocopherols cluster analysis of the nine studied Date seeds and 29 different plants oils. 
Finally, the results found in this investigation should be completed by additional studies aimed at the assessment of the biological activities and identification of the individual sterols and phenolic compounds of these oils.

\section{Conclusion}

Date-pits of nine Algerian palm varieties were studied in order to investigate their edible oil composition, as well as to evaluate their antioxidant activities. To date, nothing is known about the oil characteristics of any of the 9 samples selected in this study.

Phytochemical analysis of the date seed oils revealed their riches with many nutrients and bioactive substances such as fatty acids, sterols and tocopherols compounds. This composition suggested the use of this oil for nutritional purpose, pharmaceuticals, cosmetics and other formulations due to the high stability and resistance of date seed oil to thermal treatment for a long period of time.

Moreover, different degree of instauration of date seed oil compared to other vegetable oil make it as potential oil that can be developed for different uses. For that, more research should be conducted on date seed oil for development of edible and non-edible products and to identify and quantify the composition of polyphenols components and sterols in date seed palm by different systems.

\section{References}

[1] Matthäus B. 2011 the database "Seed Oil Fatty Acids". http://sofa.mri.bund.de/Home.htm

[2] Carlsen MH, Halvorsen BL, Holte K, Bohn SK, Dragland S, Sampson L, et al. The total antioxidant content of more than 3100 foods, beverages, spices, herbs and supplements used worldwide. Nutrition Journal. 2010;9:3.

[3] Blomhoff R, Carlsen MH, Andersen LF, Jacobs Jr DR. Health benefits of nuts: Potential role of antioxidants. British Journal of Nutrition. 2006;96(Suppl. 2):S52eS60.

[4] Habib HM, Kamal H, Ibrahim WH, Dhaheri ASA. Carotenoids, fat-soluble vitamins and fatty acid profiles of 18 varieties of date seed oil. Indus Crops Products. 2013;42:567-72.

[5] Adel RY, Boushy E, Antonius FBP. Handbook of Poultry Feed from Waste Processing and Use, 2nd Ed, Springer. 2000 , p. 159.

[6] Al-Farsi MA, Lee CY. Usage of date (Phoenix Dactylifera L.) seeds in human health and animal feed. In Preedy, VR., Watson, RR.; Patel, VB. (eds). Nuts and Seeds in Health and Disease Prevention. 2011, pp. 447-52. USA: Elsevier.

[7] Besbes S, Blecker C, Deroanne C, Drira NE, Attia H. Date seeds: Chemical composition and characteristic profiles of the lipid fraction. Food Chem. 2004a;84(4):577-84.

[8] Afiq MJA, Rahman RA, Man YBC, Al-Kahtani HA, Mansor TST. Date seed and date seed oil. International Food Research Journal. 2013;20(5):2035.

[9] Basuny AMM, AL-Marzooq MA. Production of mayonnaise from date pit oil. Food Nutr Sci. 2011;2(9):938-43.

[10] Abdalla RS, Albasheer AA, El-Hussein AM, Gadkariem EA. Physico-Chemical characteristics of date seed oil grown in Sudan. American Journal of Applied Sciences. 2012;9(7):993-9.

[11] Besbes S, Blecker C, Deroanne C, Bahloul N, Lognay G, Drira NE, Attia H. Date seed oil: Phenolic, tocopherol and sterol profies. Journal of Food Lipids. 2004c;11:251-6.

[12] Habib HM, Ibrahim WH. Effect of date seeds on oxidative damage and antioxidant status in vivo. J Sci Food Agric. 2012;91:1674-9.

[13] Duke JA. Handbook of Phytochemical Constituents of GRAS Herbs and Other Economic Plants Herbal. Boca Raton: CRC Press, Florida, 1992. p. 251.

[14] AFNOR. Corps gras, graines oléagineuses et produits dérivés. AFNOR, Paris, 1984, 1-459.

[15] Emmerie A, Engel C. Colorimetric determination of $\alpha$-tocopherol (vitamin E). Recueil des Travaux Chimiques des Pays-Bas. 1938;57:1351-5.

[16] Naudet N, Hautfenne A. Méthode normalisée pour la détermination des stérols totaux dans les huiles et graisses. Rev Fr Corps Gras. 1986;33:167.

[17] Barreto MC. Lipid extraction and cholesterol quantification. J Chem Educ. 2005;82103-104. 
[18] Molyneux P. The use of the stable free radical diphenylpicrylhydrazyl (DPPH) for estimating antioxidant activity. J Sci Technol. 2004;26(2):211-9.

[19] Abdelaziz F. Oil and fat production, Ed Dar Nacher for Egyptian universities, 1st Ed. 1993, p 31, 34.

[20] Boukouada M, Ghiaba Z, Gourine N, Bombardac I, Saidia M, Yousfi M. Chemical composition and antioxidant activity of seed oil of two algerian date palm cultivars (Phoenix dactylifera). Natural Product Communications. 2014;9(12):1777-80.

[21] Bouhlali ETC, Alem J, Ennassir M, Benlyas A, Mbark N, Zegzouti YF. Phytochemical compositions and antioxidant capacity of three date (Phoenix dactylifera L.) Seeds varieties grown in the South East Morocco. Journal of the Saudi Society of Agricultural Sciences. 2015.

[22] Hadbaoui Z, Djeridane A, Yousfi M, Saidi M, Nadjemi B. Fatty acid, tocopherol composition and the antioxidant activity of the lipid extract from the Sorghum grains growing in Algeria. Med J Nutrition Metab. 2010;3:215-20.

[23] Saafi EB, Flamini G, El Arem A, Issaoui M, Dabbou S, Ben Yahia L, Ferchichi A, Hammami M, Achour L. Compositional characteristics and aromatic profile of date palm seeds from seven varieties grown in Tunisia. Intl J Food Sci Technol. 2012;47:1903-8.

[24] Benalia M, Djeridane A, Gourine N, Nia S, Ajandouz EH, Yousfi M. Fatty acid profile, tocopherols content and antioxidant activity of Algerian pumpkin seeds oil (Cucurbita pepo L). Mediterranean Journal of Nutrition and Metabolism. 2015;8:9-25.

[25] Mistrello J, Sirisena SD, Ghavamic A, Marshalld RJ, Krishnamoorthy S. Determination of the antioxidant capacity, total phenolic and flavonoid contents of seeds from three commercial varieties of culinary dates. Intl J Food Stud. 2014;3:34-44.

[26] Warner K, Knowlton S. Frying quality and oxidative stability of high-oleic corn oils. J Am Chem Soc. 1997;74;1317-21.

[27] Al-Juhaimi F, Ghafoor K, Ozcan MM. Physical and chemical properties, antioxidant activity, total phenol and mineral profile of seeds of seven different date fruit (Phoenix dactylifera L.) varieties. Int J Food Sci Nutr. 2012;63:84-9.

[28] Sawaya WN, Khalil JK, Safi WJ. Chemical composition and nutritional quality of date seeds. Journal of Food Science. 1984;49:617-9.

[29] Yousfi M, Bombarda I, Hamia C, Djeridane A, Stocker P, Gaydou E. Fatty acid, triglyceride and tocopherol composition of Algerian Argan (Argania spinosa) fruit seed lipids. Med J Nutrition Metab. 2009;2:197-203.

[30] Lazos ES. Composition and oil characteristics of apricot, peach and cherry kernel. Grasas y Aceites. 1991;42(2):127-31.

[31] Al-Hooti S, Sidhu JS, Qabazard H. Chemical composition of seeds date fruit cultivars of United Arab Emirates. Journal of Food Science and Technology. 1998;35(1):44-6.

[32] Nehdi I, Omri S, Khalil MI, Al-Resayes SI. Characteristics and chemical composition of date palm (Phoenix canariensis) seeds and seed oil. Industrial Crops and Products. 2010;32:360-5.

[33] Yousfi M, Nedjemi B, Belal R, Benbertal D. Etude des acides gras d'huile de fruit de pistachier de l'Atlas algérien. Oil Corps Gras Li. 2003;10:425-7.

[34] Tapiero H, Nguyen BG, Couvreur P, Tew KD. Polyunsaturated fatty acids (PUFA) and eicosanoids in human health and pathologies. Biomed Pharmacother. 2002;56:215-22.

[35] Saafi EB, Trigui M, Thabet R, Hammami M, Achour L. Common date palm in Tunisia: Chemical composition of pulp and pits. Int J Food Sci Technol. 2008;43:2033-7.

[36] Al-Shahib W, Marshall RJ. Fatty acid content of the seeds from 14 varieties of date palm Pheonix dactylifera L. International Journal of Food Science and Technology. 2003b;38:709-12.

[37] Loe ML, Nollet, Toldra F. Handbook of Analysis of Active compounds In Functional Foods, 2012, CRC Press.

[38] Boukouada M, Yousfi M. Phytochemical study of date seeds lipids of three fruits (Phoenix Dactylifera L.) produced in Ouargla region. Ann Fac Sci Sci Ing. 2009;1(3):66-74.

[39] Tapiero H, Townsend DM, Tew KD. Phytosterols in the prevention of human pathologies. Biomed Pharmacother. 2003;57:321-5.

[40] Gunstone FD. Vegetable Oils in Food Technology, Blackwell publishing, CRC Press, 2002. p. 501.

[41] Yong Y, Salimon J. Characteristics of elateriospermum tapos seed oil as a new source of oil seed. Ind Crops Prod. 2006;24:146-51.

[42] Marinova E, Toneva A, Yanieslieva N. Synergistic antioxidant effect of $\alpha$-tocopherol and myricetin on the autoxidation of triacylglycerols of sunflower oil. Food Chemistry. 2008;106:628-33.

[43] Shahidi F, Camargo AC. Tocopherols and tocotrienols in common and emerging dietary sources: Occurrence, applications, and health benefits. Int J Mol Sci. 2016;17:1745.

[44] Biglar M, Khanavi M, Hajimahmoodi M, Hassani S, Moghaddam G, Sadeghi N, Oveisi MR. Tocopherol content and fatty acid profile of different iranian date seed oils. IJPR. 2012;11(3):873-8.

[45] Piombo GN, Barouh B, Barea R, Boulanger P, Brat M, Pina, Villeneuve P. Characterization of the seed oils from kiwi (Actinidia chinensis), passion fruit (Passiflora edulis) and guava (Psidium guajava). OCL. 2006;13(2-3):195-9.

[46] Siles L, Cela J, Munné-Bosch S. Vitamin E analyses in seeds reveal a dominant presence of tocotrienols over tocopherols in the Arecaceae family. Phytochemistry. 2013;95:207-14. 
[47] Besbes S, Blecker C, Deroanne C, Lognay G, Drira N, Attia H. Heating effects on some quality characteristics of date seed oil. Food Chemistry. 2005;91(3):469-76.

[48] Moure A, Cruz JM, Franco D, Manuel Dominguez J, Sineiro J, Dominguez H, Jose Nunez M, Carlos Parajo J. Natural antioxidants from residual sources. Food Chemistry. 2001;72:145-71.

[49] Adhikari P, Hwang KT, Shin MK, Lee BK, Kim SK, Kim SY, Lee KT, Kim SZ. Tocols in caneberry seed oils. Food Chemistry. 2008;111:687-90.

[50] Hildebrand DH, Terao J, Kito M. Phospholipids plus tocopherols increase soybean oil stability. Journal of the American Oil Chemists' Society. 1984;61:552-5.

[51] Wang T, Hicks KB, Moreau R. Antioxidant activity of phytosterols, oryzanol and other phytosterols conjugates. Journal of the American Oil Chemists' Society. 2002;79:1201-6.

[52] Jung MY, Yoon SH, Min DB. Effects of processing steps on the contents of minor compounds and oxidation of soybean oil. Journal of the American Oil Chemists' Society. 1989;66:118-20.

[53] Segwa T, Kamata M, Totani HY. Antioxidant activity of phospholipids for polyunsaturated fatty acids of fish oil. III. Synergism of nitrogen-containing phospholipids with tocopherols. Japan Oil Chemists' Society. 1995;44:36-42.

[54] Kazemi M, Dadkhah A. Antioxidant activity of date seed oils of fifteen varieties from iran. Orient J Chem. 2012;28(3):1201-5.

[55] Miraliakbari H, Shahidi F. Lipid class compositions, tocopherols and sterols of tree nut oils extracted with different solvents. Journal of Food Lipids. 2008;15:1-16. 